\title{
Ciência ambiental: reflexões sobre o monitoramento de resíduos de agrotóxicos em águas potável, superficial e subterrânea
}

\author{
Environmental science: reflections on the monitoring of pesticide \\ residues in drinking, superficial, and underground water
}

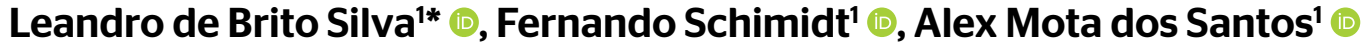

\begin{abstract}
RESUMO
As análises da água, na perspectiva da química, são realizadas, normalmente, a partir da definição dos parâmetros a serem analisados e sobre as técnicas para determinação da concentração. Desse modo, considera-se essa abordagem essencialmente cartesiana, que engessa outras possibilidades, tais como o conhecimento de outras áreas da ciência, assim como o conhecimento de fatores sociais, econômicos e de políticas públicas. Portanto, este trabalho de revisão bibliográfica pretendeu apresentar uma visão mais próxima do pensamento sistêmico e da interdisciplinaridade aplicada à análise química, com a finalidade de gerar uma discussão mais integrada sobre a análise de agrotóxicos. Os resultados revelam que a legislação ambiental brasileira sobre gestão de recursos hídricos é omissa em alguns aspectos, ainda não é plenamente aplicada em razão das carências na fiscalização e que há deficiências de integração e interação entre os diversos agentes públicos: universidades e instituições de pesquisa, agências reguladoras e demais órgãos do Poder Executivo.
\end{abstract}

Palavras-chave: qualidade da água; agrotóxicos; interdisciplinaridade; visão sistêmica; legislação; fiscalização; pesquisa.

\begin{abstract}
Water analysis, from a chemical perspective, is usually performed based on the definition of the parameters to be analyzed and on the techniques for determining the concentration. Thus, this essentially Cartesian approach is considered, which engenders other possibilities, such as knowledge of other areas of science, as well as knowledge of social, economic, and public policy factors. Therefore, this bibliographic review work aims to present a closer view of systemic thinking and interdisciplinarity applied to chemical analysis, with the purpose of generating a more integrated discussion about the analysis of pesticides. The results show that the Brazilian environmental legislation on water resources management is not yet fully implemented due to the lack of surveillance; moreover, there is a lack of integration and interaction between the various public agents: universities and research institutions, regulatory agencies, and other branches of the executive power.
\end{abstract}

Keywords: water quality; pesticides; interdisciplinarity; systemic view; legislation; surveillance; research.

\section{INTRODUÇÃO}

Quando se discute sobre a análise da água, na visão da química, pensa-se logo em parâmetros a serem analisados e sobre as técnicas para determinação da concentração. Quando o foco é a análise de agrotóxicos, geralmente são pensados os aspectos de risco à saúde humana e ao meio ambiente. Porém, o agronegócio, sendo o principal consumidor de água, é também o maior defensor dessas substâncias sob o argumento de que a aplicação de agrotóxicos aumenta a produtividade de alimentos para uma população em crescimento constante, o que gera também crescimento econômico para o país. Assim, as análises de água, a partir da visão tradicional, não levam em conta a visão sinóptica dos aspectos sociais, econômicos e políticos para sua prática. Revelam, portanto, abordagens cartesianas nas quais o conhecimento

subdividido de forma unitária leva a um pensamento seguro, porém limitado da ciência, que é utilizado para justificar essa ou aquela postura, o que condiz com os conceitos apresentados a seguir.

Segundo Sartori (2005), o conhecimento disciplinar fragmentado, característico do pensamento cartesiano, não é capaz de compreender a problemática ambiental em razão da forte tendência em separar as ações antrópicas das ações naturais, o que restringe sua capacidade de explicá-las (SARTORI, 2005). Em contraposição, Morin (1977) afirma que o pensamento sistêmico procura as articulações entre as disciplinas, as categorias cognitivas e os tipos de conhecimento, promovendo um conhecimento multidimensional, envolvendo fenômenos econômicos, sociais, culturais, psicológicos e ambientais. Assim, os pressupostos teóricos da teoria sistêmica defendem a

Programa Tecnologia de Processos Sustentáveis, Instituto Federal de Goiás - Goiânia (GO), Brasil.

*Autor correspondente: Ibs@furnas.com.br

Conflitos de interesse: os autores declaram não haver conflito de interesses. Financiamento: Furnas Centrais Elétricas S.A

Recebido: 12/11/2019 - Aceito: 18/02/2020 - Reg. Abes: 20190321 
[...] nítida tendência para a integração, nas várias ciências naturais e sociais; a integração parece se direcionar, rumo a uma teoria dos sistemas; essa teoria de sistemas pode ser uma maneira abrangente de se estudar os campos não físicos do conhecimento científico, especialmente, as ciências sociais (FALCÃO SOBRINHO et al., 2017, p. 13).

Com efeito, falta às abordagens cartesianas sobre a análise química de água, para o monitoramento de resíduos de agrotóxicos, uma visão integrada que leve em conta as influências políticas, econômicas e sociais, tais como: as alternativas para a produção de alimentos em grande escala; o manejo sustentável do meio ambiente; os impactos de atividades antrópicas, como a produção de alimentos e a geração de energia elétrica, na qualidade da água; a maneira como é feita a fiscalização dessas atividades econômicas; entre outros aspectos.

Este trabalho é uma revisão bibliográfica da legislação brasileira e de produções científicas sobre abordagens holísticas na ciência química, mais próxima da visão do pensamento sistêmico e da interdisciplinaridade aplicada à análise química com a finalidade de promover uma discussão integrada sobre o monitoramento de agrotóxicos. Isso é importante, pois segundo Falcão Sobrinho et al. (2017), os elementos químicos, físicos e biológicos se integram para formar o ambiente. Além disso, na perspectiva sistêmica, não se busca solucionar problemas, e sim oferecer suporte por meio de teorias e formulações conceituais que possam criar condições de aplicações, na realidade empírica (FALCÃO SOBRINHO et al., 2017, p. 13).

Neste estudo, são abordados temas como a produção de alimentos e seus impactos na qualidade da água, algumas formas de uso da água e como a legislação trata o assunto, os aspectos econômicos e técnicos da análise química da água, a fiscalização e sua integração sob a visão do pensamento sistêmico, além da necessidade de mudança de paradigmas na educação e na pesquisa. Os dados analisados mostram que ainda há muito que se avançar para se obter uma rede integrada de monitoramento da qualidade da água que forneça dados unificados, rápidos e confiáveis.

No decorrer deste trabalho, serão analisadas algumas atividades que impactam a qualidade da água, como a produção de alimentos, a geração de energia e próprio uso da água. A legislação brasileira sobre águas potável, superficial e subterrânea será avaliada na perspectiva da visão sistêmica e em comparação com normativas de outros países, como Estados Unidos, Canadá e União Europeia (UE), e com o que recomenda a Organização Mundial da Saúde (OMS). Por fim, serão avaliadas algumas produções científicas nacionais sobre o monitoramento de agrotóxicos nos recursos hídricos, sendo um artigo da Revista Ambiente \& Água e dois artigos da revista Química Nova. Serão exploradas também duas dissertações, uma de pós-graduação em Química e outra em Saúde Coletiva. O objetivo é verificar como autores abordam a questão da interdisciplinaridade e da visão sistêmica, qual a relação dos trabalhos com a legislação e se eles se integram com a população e os órgãos responsáveis pelo monitoramento de resíduos de agrotóxicos em água.

\section{DA PERSPECTIVA DA PRODUÇÃO DE ALIMENTOS E SEUS IMPACTOS NA ÁGUA}

O bioma cerrado, para citar um exemplo, tem sido alvo de um processo acelerado de conversão das paisagens naturais para produção de alimentos em larga escala. Esse processo tem gerado impactos profundos em decorrência da evolução do agronegócio e do consumo de agrotóxicos que têm o potencial de contaminar os suprimentos de água potável. Os agrotóxicos são aplicados diretamente sobre o solo ou plantas e podem atingir os corpos hídricos superficiais e subterrâneos, em alguns casos mananciais que têm suas águas captadas para consumo humano. $O$ grau de risco que esses contaminantes representam à saúde depende de quão tóxicos eles são, de sua quantidade na água e do grau diário de exposição de pessoas e plantas a esses produtos (USEPA, 2019).

Segundo Lopes e Albuquerque (2018), no Brasil, o movimento de adesão em massa ao uso dos agrotóxicos ocorreu a partir da década de 1960, com a implantação do Programa Nacional de Defensivos Agrícolas (PNDA). Ainda segundo os autores, "O programa vinculava a utilização dessas substâncias à concessão de créditos agrícolas, sendo o Estado um dos principais incentivadores dessa prática" (LOPES; ALBUQUERQUE, 2018, p. 519). No Cerrado, considerado o berço das águas, mas também o celeiro do mundo na produção de alimentos, o uso de agrotóxicos influencia de forma direta grandes áreas.

Uma alternativa às formas de produção tradicional de alimentos do agronegócio brasileiro são os sistemas agroflorestais, uma forma de utilização sustentável de um bioma, pois se baseia em conhecimentos tradicionais populares e resultados de pesquisas científicas para um manejo ecológico dos recursos naturais (DUTRA; SOUZA, 2017a; 2017b). Nesses sistemas, são combinadas atividades extrativas, de criação e beneficiamento, orientadas para a diversificação de espécies, a imitação da estrutura e dos padrões do ambiente natural, promovendo a integração de paisagens naturais e rurais produtivas e respeitando a capacidade do ecossistema, conforme previsto na legislação brasileira sobre agricultura orgânica e agroextrativismo orgânico (BRASIL, 2007; 2009). Portanto, o uso de técnicas de manejo e cultivo sustentáveis diminui o uso de agrotóxicos e, consequentemente, implica em menor necessidade de monitoramento dos seus impactos no meio ambiente, inclusive na água. Técnicas sustentáveis também podem diminuir o consumo de água, que tem relação direta com sua qualidade.

De acordo com Fernandes Neto e Sarcinelli (2009), para identificar os perigos relacionados ao uso da água para consumo humano, é preciso coletar informações sobre a existência de exploração agrícola na bacia de contribuição do manancial, a descarga de efluentes de agroindústrias, falhas no tratamento da água e rupturas de rede de abastecimento. $O$ conhecimento dessas informações é fundamental para um correto planejamento do monitoramento da qualidade da água, com escolhas de parâmetros químicos a serem analisados que reflitam os impactos das atividades antrópicas na região estudada.

A fiscalização dos resíduos de agrotóxicos em alimentos é efetuada pelos Laboratórios Federais de Defesa Agropecuária (LFDA) do Ministério da Agricultura, e os dados de todo o país são tabulados pela Agência Nacional de Vigilância Sanitária (ANVISA), no Programa de Análise de Resíduos de Agrotóxicos em Alimentos (PARA) (ANVISA, 2016). Porém, sobre os resíduos de agrotóxicos no solo e na água, ainda são feitos estudos de forma isolada e concentrados nas regiões próximas a zonas de atividade agropecuária. Muitos agrotóxicos são considerados persistentes no meio ambiente, sendo, portanto, uma possível fonte indireta de contaminação humana por meio da água, uma questão sobre a qual ainda se tem poucos dados (DORES; DE-LAMONICA-FREIRE, 2001; ANDRADE et al., 2011).

Do ponto de vista tributário, a legislação brasileira isenta a cobrança de Imposto Sobre Circulação de Mercadorias (ICMS) em produtos de exportação (BRASIL, 1996) - em um país onde o agronegócio é um dos setores da 
economia mais beneficiados, pois tem boa parte da produção voltada para a exportação, sendo difícil encontrar dados do percentual exportado em relação ao total produzido. Apenas reportagens e relatórios sobre recordes de exportação são divulgados. Portanto, estudos mais aprofundados devem ser feitos sobre os potenciais benefícios econômicos aos municípios e aos estados com forte atividade agrícola. Além disso, Ferreira et al. (2016) apontam que o modelo brasileiro favorece a concentração de terras e é dependente de grande volume de água; apontam, ainda, que, de acordo com a Política Nacional de Recursos Hídricos (PNRH), a agricultura irrigada é responsável pelo uso de quase $70 \%$ de toda a água consumida no Brasil. Portanto, o modelo brasileiro de produção de alimentos, além de causar impactos à qualidade da água, pode ocasionar problemas de abastecimento hídrico e consequentes problemas sociais.

\section{DAS PERSPECTIVAS DA LEGISLAÇÃO, DO USO E DA CONTAMINAÇÃO DA ÁGUA}

A outorga e a fiscalização do uso de águas superficiais e subterrâneas, inclusive para o agronegócio no Brasil, são de responsabilidade da Agência Nacional de Águas (ANA). O uso múltiplo da água para a irrigação, o abastecimento de cidades, a recreação, a geração de energia ou a disposição de efluentes, entre outros, é definido por lei, relativamente recente, que institui a PNRH (BRASIL, 1997). Além da regulação ao acesso e uso dos recursos hídricos de domínio da União, a ANA tem o papel de:

- Acompanhar a situação dos recursos hídricos do Brasil e planejar o uso da água;

- Coordenar a implantação da PNRH, estimulando a participação de representantes dos governos, usuários e comunidades;

- Elaborar estudos estratégicos, como os Planos de Bacias Hidrográficas, em parceria com instituições e órgãos do poder público (ANA, 2019).

Existem algumas legislações que visam à conservação da qualidade da água, como o Anexo XX da Portaria de Consolidação nº 5 do Ministério da Saúde, que trata sobre a potabilidade para consumo humano e define que a vigilância da qualidade da água para consumo humano e seu padrão de potabilidade ficam sob responsabilidade das Vigilâncias Sanitárias Municipais, que devem realizar o controle das análises feitas de acordo com o tipo de abastecimento (BRASIL, 2017). Outras normativas sobre a qualidade da água são: a Resolução do Conselho Nacional do Meio Ambiente (CONAMA) no 430 de 2011, que dispõe sobre as condições e os padrões do lançamento de efluentes; a Resolução do CONAMA n 357 de 2005 e suas alterações posteriores, que trata sobre as diretrizes ambientais para o enquadramento de corpos de água; e a Resolução do CONAMA no 396 de 2008, que dispõe sobre a classificação e as diretrizes ambientais para o enquadramento das águas subterrâneas. As três resoluções estabelecem limites para vários parâmetros químicos a serem monitorados, entre eles, alguns agrotóxicos. O CONAMA foi instituído em 1981, sendo o órgão consultivo e deliberativo do Sistema Nacional do Meio Ambiente (SISNAMA), que dispõe sobre a Política Nacional do Meio Ambiente (BRASIL, 2019).

Outro aspecto importante do uso da água é a geração de energia elétrica, cuja demanda também é crescente em razão do crescimento populacional e do aumento em seu consumo. A geração hidroelétrica causa impactos negativos, como as inundações e a consequente destruição de ecossistemas, mas também impactos positivos, como o turismo e a movimentação da economia das cidades banhadas pelas águas dos reservatórios. Uma contrapartida exigida pelo Estado às empresas geradoras de energia hidroelétrica é o monitoramento da qualidade da água dos reservatórios à luz das resoluções do CONAMA, sendo fiscalizadas pela ANA também em relação à segurança de barragens outorgadas por ela que, em conjunto com a Agência Nacional de Energia Elétrica (ANEEL), estabelece os monitoramentos pluviométrico, limnimétrico, fluviométrico, sedimentométrico e de qualidade da água associados a aproveitamentos hidrelétricos (ANEEL; ANA, 2010). Além disso, a ANA, em colaboração com o Operador Nacional do Sistema Elétrico (ONS), define as regras de operação dos reservatórios das usinas hidrelétricas para garantir que todos os setores que dividem o reservatório tenham acesso à água represada, garantindo o uso múltiplo da água previsto na PNRH, como a geração de energia, a irrigação, o abastecimento de cidades, entre outros.

Diante do exposto, fica evidente que a legislação deve ser revisada periodicamente para acompanhar a consolidação da ocupação antrópica, especialmente pelo agronegócio, que demanda o uso de grande quantidade de água e de novas substâncias. Os agrotóxicos já liberados para uso pelo governo brasileiro devem ser monitorados, e estudos sobre seus impactos no meio ambiente e à saúde humana devem ser realizados e divulgados. Assim como as novas substâncias recentemente aprovadas, que, além de monitoradas e estudadas, devem ser incluídas na legislação. Fernandes Neto e Sarcinelli (2009) já mostravam um comparativo entre a legislação brasileira, as recomendações da OMS e os limites dos órgãos ambientais dos Estados Unidos e do Canadá. Na Tabela 1, é apresentada uma atualização dos dados apresentados à época pelo comparativo. Nela, é possível constatar que a legislação brasileira segue o recomendado pela OMS para resíduos de agrotóxicos em água e, ainda, acrescenta outras substâncias, muitas sem limites recomendados pelas instituições citadas. A OMS possui limites mais restritivos que os órgãos ambientais dos Estados Unidos e do Canadá para a maioria dos agrotóxicos listados. A grande preocupação é com o glifosato, agrotóxico mais utilizado no Brasil e no mundo, porém sem limite recomendado para água pela OMS e com limites altos tanto no Brasil quanto nos Estados Unidos.

Em contrapartida, um atlas que compara as leis brasileira e europeia no controle dos agrotóxicos revela como nossos limites são mais altos do que os da UE, sendo 300 vezes maior para o herbicida 2,4D e para o inseticida Clorpirifós, 1.800 vezes maior para os fungicidas Mancozeb e Tebuconazol, e 5 mil vezes maior para o agrotóxico glifosato somado ao seu metabólito AMPA (BOMBARDI, 2017). Apesar disso, 166 agrotóxicos foram aprovados para uso no Brasil apenas em 2019, uma fatia significativa das mais de 2 mil substâncias e formulações atualmente em uso no país.

Desses 2 mil tipos de agrotóxicos, apenas 16 receberam a classificação de "pouco tóxico", segundo a classificação da ANVISA. Enquanto isso, 33 foram avaliados como "extremamente tóxico", que é o nível mais alto de toxicidade. Todos eles são parcialmente ou totalmente produzidos por empresas de fora do Brasil, atraídas por incentivos fiscais. Desde 2004, a Lei no 10.925 reduziu a zero as alíquotas do PIS/PASEP e da Contribuição para o Financiamento da Seguridade Social (COFINS) para importação e comercialização de fertilizantes e agrotóxicos. Os agrotóxicos têm, ainda, redução de $60 \%$ da base de cálculo do ICMS (GRIGORI, 2019).

Apesar de toda a legislação existente para o monitoramento das águas proposta pelo Estado brasileiro, atualmente, ainda existem políticas públicas que fomentam o uso e o comércio de agrotóxicos, mantidas pela influência da bancada ruralista no Congresso Nacional (LOPES; ALBUQUERQUE, 2018). 


\section{DAS PERSPECTIVAS DA ANÁLISE QUÍMICA DA ÁGUA, DA FISCALIZAÇÃO E DOS RISCOS À SAÚDE}

A análise química de substâncias utilizadas como agrotóxicos nas lavouras é complexa e cara, pois envolve, em sua maioria, técnicas de cromatografia que requerem mão de obra altamente especializada e equipamentos importados de alta tecnologia, cujo preço de aquisição ultrapassa facilmente 1 milhão de reais, além dos custos anuais com manutenção, consumíveis e insumos para preparação de amostras. Portanto, não é qualquer instituição, seja pública ou privada, que tem esses instrumentos disponíveis. Disso decorre a baixa disponibilidade de laboratórios preparados para análise de agrotóxicos de forma a atender à legislação ambiental brasileira na íntegra. O custo por análise também é relativamente alto, na casa dos milhares de reais por amostra, dependendo do rol de substâncias a serem analisadas, o que inibe a contratação de análises e o monitoramento de resíduos de agrotóxicos em água.

A responsabilidade pela fiscalização do monitoramento de resíduos de agrotóxicos em água é compartilhada entre União, estados e municípios (ANA, 2019).

Tabela 1 - Comparação entre os valores máximos permitidos dos agrotóxicos regulamentados pela Portaria de Consolidação no 5/2017 do Ministério da Saúde e diferentes normatizações internacionais, em $\mu \mathrm{g} / \mathrm{L}$.

\begin{tabular}{|c|c|c|c|c|}
\hline Parâmetro & $\begin{array}{c}\text { Portaria no } \\
\text { 5/2017 do MS }\end{array}$ & $\begin{array}{l}\text { Guias } \\
\text { OMS' }\end{array}$ & USEPA $^{1}$ & $\begin{array}{l}\text { Health } \\
\text { Canada }^{1}\end{array}$ \\
\hline Alaclor & 20 & 20 & 2 & \\
\hline Aldrin/Dieldrin & 0,03 & 0,03 & & 0,7 \\
\hline Atrazina & 2 & 2 & 3 & 5 \\
\hline Clordano (isômeros) & 0,2 & 0,2 & 2 & \\
\hline Carbendazim + benomil & 120 & & & \\
\hline $2,4 \mathrm{D}$ & 30 & 30 & 70 & 100 \\
\hline DDT (isômeros) & 1 & 1 & & \\
\hline Endossulfan & 20 & & & \\
\hline Endrin & 0,6 & 0,6 & 2 & \\
\hline Glifosato & 500 & & 700 & 280 \\
\hline $\begin{array}{l}\text { Heptacloro e } \\
\text { heptacloro epóxido }\end{array}$ & 0,03 & & 0,4 e 0,2 & \\
\hline Hexaclorobenzeno & 1 & & 1 & \\
\hline Lindano (g - BHC) & 2 & 2 & 0,2 & \\
\hline Mancozebe & 180 & & & \\
\hline Metolacloro & 10 & 10 & & 50 \\
\hline Metoxicloro & & 20 & 40 & 900 \\
\hline Molinato & 6 & 6 & & \\
\hline Pendimetalina & 20 & 20 & & \\
\hline Pentaclorofenol & 9 & 9 & 1 & 60 \\
\hline Permetrina & 20 & $300^{(2)}$ & & \\
\hline Profenofós & 60 & & & \\
\hline Propanil & 20 & & & \\
\hline Simazina & 2 & 2 & 4 & 10 \\
\hline Tebuconazol & 180 & & & \\
\hline Trifluralina & 20 & 20 & & 45 \\
\hline
\end{tabular}

MS: Ministério da Saúde; OMS: Organização Mundial da Saúde; USEPA: United States Environmental Protection Agency;'para os campos não preenchidos, não há previsão de valor guia ou valores máximos permitidos quando utilizada na água como larvicida; Fonte: Brasil (2017); Health Canada (2017); United States Environmental Protection Agency (2019); WHO (2011).
Segundo Aranha e Rocha (2019), dos 5.570 municípios brasileiros, 2.931 não realizaram testes nas suas redes de abastecimento entre 2014 e 2017. E, apesar de se tratar de informação pública, os testes não são divulgados de forma compreensível para a população, deixando os brasileiros no escuro sobre os riscos que correm ao beber um copo d'água. Um coquetel que mistura diferentes agrotóxicos foi encontrado na água consumida em uma de cada quatro cidades do Brasil, entre 2014 e 2017. Ainda segundo os autores, nesse mesmo período, as empresas de abastecimento de 1.396 municípios detectaram todos os 27 agrotóxicos, para os quais a realização de testes é determinada por lei, e 21 deles estão proibidos na UE em razão dos riscos que oferecem à saúde e ao meio ambiente. Desses, 16 são classificados pela ANVISA como extremamente ou altamente tóxicos e 11 estão associados ao desenvolvimento de doenças crônicas como câncer, malformação fetal, disfunções hormonais e reprodutivas (ARANHA; ROCHA, 2019).

Percebe-se que os órgãos ambientais brasileiros ainda são complacentes com o baixo índice de monitoramento de muitas substâncias em água e exigem, geralmente, poucos pontos e pouca frequência de amostragem da lista de agrotóxicos contida na legislação. O Anexo XX da Portaria de Consolidação no 5/2017 do Ministério da Saúde, que trata sobre a potabilidade para consumo humano; e a Resolução do CONAMA nº 357/2005, que versa sobre as diretrizes ambientais para o enquadramento dos usos de corpos de água, estabelecem limites para vários parâmetros químicos a serem monitorados, entre eles os agrotóxicos, mas não indicam a periodicidade do monitoramento, nem o número de pontos a serem monitorados, e ainda não estipulam metas de qualidade e prazos a serem cumpridos.

Comparando-se com a Diretiva Quadro D’Água (DQA), estabelecida na UE no ano 2000, percebe-se as deficiências da legislação brasileira, pois a DQA define a frequência de monitoramento para parâmetros químicos, biológicos e hidromorfológicos, estabelece um ponto de monitoramento a cada $1.000 \mathrm{~km}^{2}$ e quais substâncias são prioritárias para se monitorar, além de traçar metas para o alcance de bom estado ecológico das águas nos países-membros da UE (SILVA; FERREIRA; POMPÊO, 2013).

A maioria das pesquisas sobre qualidade da água no Brasil está concentrada em universidades e instituições públicas de pesquisa, algumas das quais serão analisadas neste trabalho. Verifica-se maior preocupação da academia com relação aos impactos de poluentes na água, porém os estudos são isolados e cada instituição analisa sua área de abrangência. Não há uma uniformização dos parâmetros analisados, falta comunicação entre os agentes citados e há baixa correlação entre as áreas da ciência (química, biologia, geografia, engenharia ambiental etc.) dentro de uma mesma instituição. Falta ainda uma integração com a ANVISA, com a exceção de poucas instituições que participam da Rede Brasileira de Laboratórios Analíticos em Saúde (REBLAS). Por fim, nem todos os laboratórios credenciados realizam análises de agrotóxicos em água, e nem todos os estados possuem laboratórios credenciados (ANVISA, 2019).

Do ponto de vista do agronegócio, grande gerador de resíduos de agrotóxicos na água, poucos monitoramentos são feitos ou financiados pelos grandes produtores brasileiros, apesar de alguns agrotóxicos serem classificados como "cancerígeno provável” pela OMS, por exemplo, o glifosato (WHO, 2015). Apesar da toxicidade, o glifosato é um dos agrotóxicos mais utilizados do mundo, presente em vários produtos herbicidas como o Roundup, o nome comercial mais conhecido deles. Entre outros riscos do glifosato à saúde humana, estão potenciais impactos adversos sobre o desenvolvimento fetal, nos processos metabólicos e em órgãos como o fígado e o rim (BENBROOK, 2016).

Em contrapartida, estudos financiados pelos fabricantes de agrotóxicos e divulgados na mídia geralmente apontam para a segurança das substâncias 
usadas (REDAÇÃO GLOBO RURAL, 2018; AFP, 2018). Burtscher-Schaden, Clausing e MPhil (2017) acusam esses fabricantes de comprar cientistas e influenciar agências reguladoras em diversos países de forma a evitar o banimento dos agrotóxicos mais utilizados do mundo e que são uma fonte muito lucrativa para as empresas que os produzem.

\section{O PONTO DE VISTA DA PESQUISA, DA INTERDISCIPLINARIDADE E DA VISÃO SISTÊMICA}

Em uma das publicações analisadas, pesquisa realizada pela Fundação Oswaldo Cruz (FIOCRUZ) e publicada na Revista Ambiente \& Água, Carmo et al. (2013) analisaram a toxidade dos herbicidas Atrazina e Simazina, que apesar de parcialmente solúveis, podem ser detectados em águas subterrâneas e superficiais. Ambas as substâncias são utilizadas no controle de ervas daninhas em plantações de cana-de-açúcar e milho e não são citadas pela Portaria nº 5/2017 do Ministério da Saúde por serem consideradas pouco tóxicas, porém com alta capacidade de interferência nos sistemas nervoso e endócrino humanos, segundo os autores. A pesquisa conclui que os compostos estudados têm boa mobilidade em água-solo e, por isso, os autores sugerem o monitoramento de resíduos em águas superficiais e subterrâneas, além de mais investigações a respeito da degradação e da toxicidade dos compostos. Observa-se, neste artigo, a necessidade de análise conjunta com a hidrogeologia, de modo a compreender a disponibilidade e o comportamento das substâncias agrotóxicas na água e no solo. Essa abordagem se faz necessária, pois dependendo das características hidrogeológicas, o poluente pode se propagar de forma mais rápida ou mais lenta, ou até mesmo se diluir ou degradar no percurso do curso hídrico.

Em uma segunda produção científica analisada, publicada na revista Química Nova, Andrade et al. (2011), da Universidade Federal de Viçosa (UFV), identificaram o risco de contaminação de águas superficiais e subterrâneas por pesticidas em municípios do Alto Paranaíba, Minas Gerais, utilizando o índice GUS (Grounwater Ubiquity Score) e o método de Goss, respectivamente. Os autores analisaram dados climatológicos obtidos no Instituto Nacional de Meteorologia (INMET) e sobre os tipos de solo levantados pela Empresa Brasileira de Pesquisa Agropecuária (EMBRAPA). Realizaram o levantamento das culturas praticadas na região, identificaram os princípios ativos, a classe química e a classificação toxicológica e ambiental. Dos princípios ativos estudados, $26,3 \%$ do total foram identificados como os de maior chance de serem transportados e, consequentemente, de contaminar águas superficiais. Entre os agrotóxicos listados, apenas Atrazina e Endossulfan estão referenciados para monitoramento na Resolução CONAMA no 357 (BRASIL, 2005). Em relação às águas subterrâneas, observa-se que, segundo os critérios utilizados (índice Groundwater Ubiquity Score GUS e United States Environmental Protection Agency - US EPA), 36,8\% se enquadram como contaminantes em potencial. Dos mais de 20 agrotóxicos listados, apenas Alacloro, Aldicarbe, Atrazina e Bentazona são relacionados para monitoramento na Resolução CONAMA no 396 (BRASIL, 2008). Este artigo também mostra a importância de se correlacionar dados hidrogeológicos com informações químicas de propriedade e toxidade dos agrotóxicos estudados. Ressalta também que a legislação brasileira é omissa sobre muitas substâncias com grande potencial de contaminação de águas superficiais e subterrâneas.

Em mais um artigo da Revista Química Nova, pesquisadores da Universidade Federal do Mato Grosso (UFMT) trabalharam em parceria com profissionais da Universidade de Cuiabá (UNIC). Dores e De-Lamonica-Freire (2001) identificaram agrotóxicos em águas utilizadas para consumo humano em Primavera do Leste, Mato Grosso, entre eles:

- Os com maior mobilidade no meio ambiente, como o glifosato;

- Os mais persistentes no solo, aparecendo a Atrazina e a Simazina, estudados também por Carmo et al. (2013), da FIOCRUZ, e com meia vida entre um mês até mais de seis meses;

- Os mais frequentemente encontrados em águas da região, entre eles, novamente, a Atrazina e a Simazina.

Os autores concluem que o período de chuvas coincide com o período de aplicação dos agrotóxicos e que, portanto, os riscos de contaminação de águas superficiais e subterrâneas não podem ser desprezados. Essa pesquisa também apresenta diversas substâncias que não estão referenciadas na legislação brasileira para monitoramento compulsório.

Analisando a dissertação de mestrado em Química pela Universidade Estadual Paulista "Júlio de Mesquita Filho" (UNESP) Araraquara, Mendonça (2018) focou seu estudo na determinação de glifosato e seu metabólito AMPA nas águas superficiais da Bacia do Paraná 3, no aprimoramento do preparo de amostras e na redução do uso de solventes na análise. A autora detectou baixas concentrações de ambas as substâncias pesquisadas na região estudada, menores do que os limites preconizados na legislação. Ela sugere maiores investigações e que o glifosato não permanece em águas superficiais, sendo provavelmente fixado no solo. Porém, não foram avaliados dados pluviométricos e se a amostragem coincidiu com o período de cultivo à aplicação de agrotóxicos. Um dos pontos positivos da pesquisa foi o aperfeiçoamento do método analítico, reduzindo os seus custos, o que pode estimular a adoção da metodologia para o monitoramento de glifosato e AMPA.

Mata (2010), em sua dissertação, pesquisou agrotóxicos provenientes da agricultura realizada no município de Rio Branco, no estado do Acre, e utilizou uma técnica analítica conhecida como ELISA, de custo mais acessível e menos complexa do que a cromatografia. Encontrou inseticidas organofosforados e carbamatos acima dos limites máximos da legislação em 29,4\% das amostras de açudes da região, e mostrou que a concentração de resíduos em águas superficiais acompanha a sazonalidade agrícola, ou seja, a maior concentração de resíduos de agrotóxicos em águas superficiais ocorre justamente em períodos de intensificação da produção agrícola e de maiores volumes de chuva, que ocasiona o carregamento desses resíduos até os rios. A autora destaca também a importância do monitoramento para a vigilância em saúde de populações vulneráveis.

Os estudos analisados mostram que a possibilidade de contaminação das águas por resíduos de agrotóxicos é real, o que justifica a existência de um programa de monitoramento de água em moldes semelhantes ao programa de alimentos organizado pela ANVISA. É verificado um enfoque na técnica analítica em si e na quantificação de substâncias, visando alternativas com menores custos e tempos de análise, que são fatores positivos para favorecer o fortalecimento do monitoramento da qualidade da água. Porém, há espaço para melhora na correlação a fatores ambientais como pluviosidade, vazão do corpo hídrico, tipos de solo e erosões, interações dos agrotóxicos com os organismos aquáticos, entre outros. Podem ser aprimorados estudos de depuração dos agrotóxicos nos corpos hídricos, de bioacumulação, de uso de geoprocessamento no tratamento dos dados obtidos etc.

Além disso, nos estudos analisados, não há evidências de que os resultados ou as sugestões tenham sido encaminhados aos órgãos de fiscalização e controle como a ANVISA, a ANA ou o CONAMA. Também não foi evidenciada a 
comunicação com a população afetada pelos resíduos de agrotóxicos em água, nem sobre as indicações técnicas alternativas ou de substâncias menos nocivas que sejam substitutas aos atuais agrotóxicos comerciais. Não há ainda qualquer indicativo de contato ou parcerias com empresas privadas que possam fomentar os estudos e/ou utilizar os dados produzidos para planejar novos produtos, técnicas de cultivo ou de aplicação menos agressivas. Falta, portanto, a adoção de uma visão realmente sistêmica do monitoramento ambiental.

É necessária maior integração entre o Estado, a pesquisa científica e a iniciativa privada, que é a produtora de substâncias potencialmente contaminantes da água e prejudiciais à saúde. Há também a urgente necessidade de conscientizar a população, principalmente aquela diretamente afetada pelo uso de agrotóxicos e pelo consumo de água com seus resíduos. Uma iniciativa interessante, nesse sentido, são as recomendações do relatório do programa de análise de resíduos de agrotóxicos em alimentos, como:

- O desenvolvimento de projetos de educação sanitária no campo, pelas empresas registrantes de agrotóxicos;

- A intensificação de ações de fiscalização pelos órgãos de fiscalização e controle;

- O encaminhamento aos órgãos de repressão, como a polícia federal, das ocorrências de detecções de resíduos de agrotóxicos banidos ou não registrados no país (ANVISA, 2016).

Infelizmente, recomendações semelhantes não estão disponíveis para resíduos de agrotóxicos na água ou no solo.

Outro aspecto importante é a carência da participação popular e do agronegócio na gestão da água, por exemplo, nos Comitês de Bacia Hidrográfica e nos Conselhos de Recursos Hídricos dos Estados e Municípios, importantes para o gerenciamento de recursos hídricos e previstos pela Lei das Águas (BRASIL, 1997). Nos estudos analisados, não foi verificada comunicação desses agentes com a academia ou sua participação nos comitês de gestão dos corpos hídricos estudados. A pesquisa de metodologias alternativas e mais baratas é importante, assim como a quantificação de substâncias, mas não deve ser feita de forma isolada. É preciso integrar uma rede de dados e um plano periódico de monitoramento da água alinhado a projetos de expansão industrial e desenvolvimento econômico. Assim, a academia pode, além de gerar bons recursos humanos, contribuir para o desenvolvimento sustentável do país e assegurar a segurança da saúde coletiva da população. Os dados produzidos pelos diversos agentes devem integrar um banco de dados e fazer parte de relatórios com linguagem unificada, acessível e que sejam de fácil acesso a todos.

Além das dificuldades no acesso às informações sobre o mercado de agrotóxicos, outro problema é a falta de estrutura dos órgãos de fiscalização brasileiros. Júnia (2012), pesquisadora da FIOCRUZ, apontava que, no ano de 2012, enquanto a Agência de Proteção Ambiental (EPA), nos Estados Unidos, tinha 850 técnicos, a ANVISA tinha 26. Somados os profissionais do Instituto Brasileiro do Meio Ambiente e dos Recursos Naturais Renováveis (IBAMA) e do Ministério da Agricultura, não chegava a 50 o número de técnicos responsáveis pela fiscalização de resíduos de agrotóxicos em água, mesmo considerando que o Brasil tem um mercado $10 \%$ maior do que o mercado estadunidense. Outra diferença entre Brasil e Estados Unidos apontada pela autora eram os valores pagos pelo registro e pela reavaliação dos agrotóxicos. No Brasil, o custo para registro variava entre 50 e mil dólares. Já nos Estados Unidos, esse valor chega a 630 mil dólares. A reavaliação e a manutenção anual não são cobradas no Brasil, enquanto nos Estados Unidos as empresas precisam pagar
150 mil dólares em caso de reavaliação e de 100 a 425 dólares para manutenção anual. São esses montantes que arcam com a estrutura de funcionamento da fiscalização nos Estados Unidos e que faltam para estruturar a fiscalização brasileira (JÚNIA, 2012).

\section{CONSIDERAÇÕES FINAIS}

Diante do exposto, conclui-se que o pensamento sistêmico é de suma importância para as ciências ambientais, no contexto da gestão dos recursos hídricos e seus impactos na população humana, pois não há como dissociar os diversos aspectos: legislação, políticas públicas, produção industrial, organizações sociais, dificuldades técnicas e econômicas, desenvolvimento científico e tecnológico, e níveis de educação e cultura de uma sociedade. A legislação ambiental brasileira sobre gestão de recursos hídricos é relativamente recente, ainda não plenamente aplicada em razão das carências na fiscalização, não completamente internalizada pelo Estado, evidenciado pelas deficiências de integração e interação entre os diversos agentes públicos: universidades, instituições de pesquisa, agências reguladoras e demais órgãos do Poder Executivo para garantir a completa gestão da água e a segurança da qualidade e da quantidade no abastecimento à população.

Portanto, é importante que uma instituição pública de educação, como o Instituto Federal de Goiás (IFG), possua um Mestrado de Tecnologias de Processos Sustentáveis e uma linha de pesquisa em fontes alternativas de água, que estimulem profissionais a:

- Buscar melhores práticas para gestão desse recurso natural finito;

- Utilizar do pensamento sistêmico para promover a extensão e a integração com demais setores da sociedade.

É necessário também que seja dado enfoque aos agrotóxicos também em cursos de graduação, como fizeram Braibante e Zappe (2012) ao trabalharem conteúdos de química, bem como as consequências de sua utilização no meio ambiente e para a saúde do trabalhador. É por meio da educação científica, da sensibilização e dos esforços conjuntos entre institutos e centros relacionados com a água que poderemos preparar uma geração para o desenvolvimento sustentável (UNESCO, 2015; 2019).

Neste trabalho, não foram verificadas as formas de estruturação e financiamento das organizações sociais de gestão da água, nem os projetos de extensão existentes na academia, que podem vir a ser objeto de estudos posteriores. Outras sugestões para trabalhos futuros são a realização de estudos georreferenciados e o levantamento estatístico da relação entre a atividade agrícola, a contaminação da água, a disponibilidade de recursos hídricos e os impactos nas economias locais. Não se pretendeu esgotar todos os aspectos sobre o uso e a gestão da água e nem sobre o monitoramento de resíduos de agrotóxicos nesse recurso natural, mas levantar uma reflexão sobre o tema e os pontos apresentados, bem como estimular pesquisas sob outras óticas e abordagens, para atingirmos o objetivo de assegurar a disponibilidade de água a gerações futuras.

\section{CONTRIBUIÇÕES DOS AUTORES}

Silva, L. B.: Conceituação, Curadoria de Dados, Análise Formal, Investigação, Obtenção de Financiamento. Schimdt, F: Supervisão, Validação, Visualização, Escrita - Primeira Redação. Santos. A. M.: Supervisão, Validação, Visualização, Escrita - Revisão e Edição. 


\section{REFERÊNCIAS}

AFP. Bayer: glifosato é seguro e não cancerígeno. Estado de Minas, 2018. Disponível em: https://www.em.com.br/app/noticia/ internacional/2018/08/11/interna_internacional,979593/bayer-glifosato-eseguro-e-nao-cancerigeno.shtml. Acesso em: 16 jun. 2019.

AGÊNCIA NACIONAL DE AGUAS (ANA). Sobre a ANA. Brasil: ANA. Disponivel em: Disponível em: https://www.ana.gov.br/acesso-a-informacao/ institucional/sobre-a-ana. Acesso em: 8 jun. 2019.

AGÊNCIA NACIONAL DE ENERGIA ELÉTRICA (ANEEL); AGÊNCIA NACIONAL DE AGUAS (ANA). Resolução Conjunta no 3, de 10 de agosto de 2010. ANA, 2010. Disponível em: http://arquivos.ana.gov.br/infohidrologicas/ cadastro/ResolucaoConjunta_n_003-2010.pdf. Acesso em: 8 jun. 2019.

AGÊNCIA NACIONAL DE VIGILÂNCIA SANITÁRIA (ANVISA). Laboratórios analíticos habilitados na REBLAS. ANVISA Disponível em: http://antigo. anvisa.gov.br/rede-de-laboratorios. Acesso em: 11 jun. 2019.

AGÊNCIA NACIONAL DE VIGILÂNCIA SANITÁRIA (ANVISA). Programa de análise de resíduos de agrotóxicos em alimentos. Relatório das análises de amostras monitoradas no período de 2013 a 2015. Brasília: ANVISA, 2016. Disponível em: https://portrasdoalimento.info/wp-content/ uploads/2O2O/O9/Relatorio-PARA-2013-2015_VERSAO-FINAL.pdf. Acesso em: 4 jun. 2019.

ANDRADE, A.S. et al. Análise de risco de contaminação de águas superficiais e subterrâneas por pesticidas em municípios do Alto Paranaíba - MG. Química Nova, v. 34, n. 7. p. 1129-1135, 2011. https://doi.org/10.1590/SO10040422011000700005

ARANHA, A.; ROCHA, L. Coquetel perigoso: Levantamento aponta que 1 a cada 4 cidades brasileiras tem água contaminada por 27 tipos de agrotóxicos. UOL Notícias, 15 abr. 2019. Disponível em: https://noticias.uol. com.br/reportagens-especiais/coquetel-com-agrotoxicos-esta-presente-naagua-de-1-a-cada-4-municipios/index.htm. Acesso em: 16 jun. 2019.

BENBROOK, C.M. Trends in glyphosate herbicide use in the United States and globally. Environmental Sciences Europe, v. 28, n. 3, 2016. Disponível em: https://enveurope.springeropen.com/articles/10.1186/s12302-016-0070O. Acesso em: 16 jun. 2019. https://doi.org/10.1186/s12302-016-0070-0

BOMBARDI, L.M. Atlas: Geografia do Uso de Agrotóxicos no Brasil e Conexões com a União Europeia. São Paulo: Laboratório de Geografia Agrária, USP, 2017. 296 p.

BRAIBANTE, M.E.F.; ZAPPE, J.A. A Química dos agrotóxicos. Química Nova na Escola, v. 34, n. 1, p. 10-15, fev. 2012.

BRASIL. Decreto no 6.323, de 27 de dezembro de 2007. Regulamenta a Lei n. 10.831, de 23 de dezembro de 2003, que dispõe sobre a agricultura orgânica, e dá outras providências. Brasil, 2007. Disponível em: http://www. planalto.gov.br/ccivil_03/_ato2007-2010/2007/Decreto/D6323.htm. Acesso em: 3 jun. 2019.

BRASIL. Lei complementar no 87, de 13 de setembro de 1996. Lei Kandir. Brasil, 1996. Disponível em: http://www.planalto.gov.br/ccivil_O3/leis/lcp/ Icp87.htm. Acesso em: 11 jun. 2019.

BRASIL. Lei no 9.433, de 8 de janeiro de 1997. Institui a Política Nacional de Recursos Hídricos. Brasil, 1997. Disponível em: http://www.planalto.gov. br/ccivil_O3/leis//9433.htm. Acesso em: 4 jun. 2019.
BRASIL. Ministério da Agricultura, Pecuária e Abastecimento. Laboratórios Federais de Defesa Agropecuária - LFDA. Brasil, 2016. Disponível em: https://www.gov.br/agricultura/pt-br/assuntos/laboratorios/lfda. Acesso em: 2 jun. 2019.

BRASIL. Ministério da Agricultura, Pecuária e Abastecimento. Ministério do Meio Ambiente. Instrução Normativa Conjunta no 17, de 28 de maio de 2009. Brasil, 2009. Disponível em: http://www.agricultura.gov.br/assuntos/ sustentabilidade/organicos/legislacao/portugues/instrucao-normativaconjunta-mapa-mma-no-17-de-28-de-maio-de-2009-extrativismosustentavel-organico.pdf. Acesso em: 3 jun. 2019.

BRASIL. Ministério da Saúde. Portaria de Consolidação no 5, de 28 de setembro de 2017. ANEXO XX. Do Controle e da Vigilância da Qualidade da Água para Consumo Humano e seu Padrão de Potabilidade. Brasil, 2017. Disponível em: http://bvsms.saude.gov.br/bvs/saudelegis/gm/2017/ prc0005_03_10_2017.html/. Acesso em: 8 jun. 2019.

BRASIL. Ministério do Meio Ambiente. O que é o CONAMA? Disponível em: http://www2.mma.gov.br/port/conama/. Acesso em: 2 jun. 2019.

BRASIL. Ministério do Meio Ambiente. Resolução CONAMA no 357, de 17 de março de 2005. Dispõe sobre a classificação dos corpos de água e diretrizes ambientais para o seu enquadramento, bem como estabelece as condições e padrões de lançamento de efluentes, e dá outras providências. Brasil, 2005. Disponivel em: http://www2.mma.gov.br/port/conama/ legiabre.cfm?codlegi=459. Acesso em: 28 set. 2019.

BRASIL. Ministério do Meio Ambiente. Resolução CONAMA no 396, de 3 de abril de 2008. Dispõe sobre a classificação e diretrizes ambientais para o enquadramento das águas subterrâneas e dá outras providências. Brasil, 2008. Disponível em: http://www2.mma.gov.br/port/conama/legiabre. cfm?codlegi=562. Acesso em: 28 set. 2019.

BRASIL. Ministério do Meio Ambiente. Resolução CONAMA no 430, de 13 de março de 2001. Dispõe sobre as condições e padrões de lançamento de efluentes, complementa e altera a Resolução no 357, de 17 de março de 2005, do Conselho Nacional do Meio Ambiente. Brasil, 2005. Disponível em: $\quad$ http://www2.mma.gov.br/port/conama/legiabre.cfm?codlegi=646. Acesso em: 28 set. 2019.

BURTSCHER-SCHADEN, H.; CLAUSING, P.; MPHIL, C. R. Glyphosate \& Cancer: Buying Science. How industry strategized (and regulators colluded) in an attempt to save the world's most widely used herbicide from a ban. Global 2000, 2017. Disponível em: https://www.global2000. at/sites/global/files/Glyphosate_and_cancer_Buying_science_EN_O.pdf. Acesso em: 28 set. 2019.

CARMO, D.A. et al. Comportamento ambiental e toxidade dos herbicidas atrazina e simazina. Revista Ambiente \& Água, v. 8, n. 1, p. 133-143, 2013. https://doi.org/10.4136/ambi-agua.1073

DORES, E.F.G.C.; DE-LAMONICA-FREIRE, E.M. Contaminação do Ambiente Aquático por Pesticidas. Estudo de Caso: Águas Usadas para Consumo Humano em Primavera do Leste, Mato Grosso - Análise Preliminar. Química Nova, v. 24, n. 1, p. 27-36, 2001. https://doi.org/10.1590/S010040422001000100007

DUTRA, R.M.S.; SOUZA, M.M.O. Agroextrativismo e geopolítica da natureza. Ateliê Geográfico, Goiânia, v. 11, n. 3, p. 110-133, dez. 2017a. https://doi. org/10.5216/ag.v11i3.43644 
DUTRA, R.M.S.; SOUZA, M.M.O. Cerrado, Revolução Verde e evolução do consumo de agrotóxicos. Sociedade \& Natureza, Uberlândia, v. 29, n. 3, p. 469-484, set./dez. 2017b. https://doi.org/10.14393/SN-v29n3-2017-8

FALCÃO SOBRINHO, J.F. et al. Natureza, Meio Ambiente e a Teoria Geral dos Sistemas: Bases Ambientais, Econômicas e Jurídicas. Holos, ano 33, v. 8, p. 1-22, 2017. https://doi.org/10.15628/holos.2017.3485

FERNANDES NETO, M.L.; SARCINELLI, P.N. Agrotóxicos emágua para consumo humano: uma abordagem de avaliação de risco e contribuição ao processo de atualização da legislação brasileira. Engenharia Sanitária e Ambiental, v. 14, n. 1, p. 69-78, jan./mar. 2009. https://doi.org/10.1590/S1413-41522009000100008

FERREIRA, M.J.M. et al. Gestão e uso dos recursos hídricos e a expansão do agronegócio: água para quê e para quem? Ciência \& Saúde Coletiva, v. 21, n. 3, p. 743-752, 2016. https://doi.org/10.1590/1413-81232015213.21012015

GRIGORI, P. Aprovações de agrotóxicos de governo Bolsonaro beneficiam empresas estrangeiras. Dos 166 pesticidas liberados neste ano, apenas $5 \%$ são totalmente produzidos em solo nacional. Por trás do Alimento, 14 maio 2019. Disponível em: https://portrasdoalimento.info/2019/05/14/ aprovacoes-de-agrotoxicos-de-governo-bolsonaro-beneficiam-empresasestrangeiras/\#. Acesso em: 16 jun. 2019.

HEALTH CANADA. Guidelines for Canadian Drinking Water Quality: Summary Table. Health Canada, 2017. Disponível em: https://www.canada. ca/en/health-canada/services/environmental-workplace-health/reportspublications/water-quality/guidelines-canadian-drinking-water-qualitysummary-table.html. Acesso em: 9 jun. 2019.

JÚNIA, R. Agrotóxicos: um mercado bilionário e cada vez mais concentrado. Escola Politécnica de Saúde Joaquim Venâncio, 2012. Disponível em: http://www.epsjv.fiocruz.br/noticias/reportagem/agrotoxicos-um-mercadobilionario-e-cada-vez-mais-concentrado. Acesso em: 16 jun. 2019.

LOPES, C.V.A; ALBUQUERQUE, G.S.C.Agrotóxicoseseusimpactosnasaúdehumana e ambiental: uma revisão sistemática. Saúde em Debate, v. 42, n. 117, p. 518-534, 2018. Disponível em: http://www.scielo.br/pdf/sdeb/v42n117/0103-1104-sdeb-42-117-0518.pdf. Acesso em: 12 ago. 2019. https://doi.org/10.1590/0103-1104201811714

MATA, J.F. Contaminação de águas superficiais por residuos de agrotóxicos provenientes da agricultura no município de Rio Branco/AC. 108f. Dissertação (Mestrado em Saúde Coletiva) - Centro de Ciências da Saúde e do Desporto, Universidade Federal do Acre, Rio Branco, 2010.

MENDONÇA, C.F.R. Determinação de glifosato e AMPA nas águas superficiais da bacia do Paraná 3. 129f. Dissertação (Mestrado em Química) - Instituto de Química, Universidade Estadual Paulista "Júlio de Mesquita Filho", Araraquara, 2018.
MORIN, E. O Método 1: A Natureza da Natureza. 2. ed. Portugal: Publicações Europa-América, 1977. 361 p. Disponível em: http://abdet.com. br/site/wp-content/uploads/2015/O4/A-Natureza-da-Natureza.pdf. Acesso em: 3 jun. 2019.

REDAÇÃO GLOBO RURAL. Glifosato é seguro, defende Monsanto. Globo Rural, 2018. Disponível em: https://revistagloborural.globo.com/Noticias/ Agricultura/noticia/2018/08/glifosato-e-seguro-defende-monsanto.html. Acesso em: 9 jun. 2019.

SARTORI, R.C. O Pensamento Ambiental Sistêmico: Uma Análise da Comunicação Científica da ESALQ/USP. 128f. Dissertação (Mestrado em Ecologia de Agroecossistemas) - Escola Superior de Agricultura "Luiz de Queiroz", Universidade de São Paulo, Piracicaba, 2005. Disponível em: http://www.teses.usp.br/teses/disponiveis/91/91131/tde-15072005-145343/ptbr.php. Acesso em: 10 jun. 2019

SILVA, S.C.; FERREIRA, T.; POMPÊO, M.L.M. Diretiva Quadro D’Água: Uma Revisão Crítica e a Possibilidade de Aplicação no Brasil. Ambiente \& Sociedade, São Paulo, v. 16, n. 1, p. 39-58, jan./mar. 2013. https://doi. org/10.1590/S1414-753X2013000100004

UNITED NATIONS EDUCATIONAL, SCIENTIFIC AND CULTURAL ORGANIZATION (UNESCO). International Initiative on Water Quality. Paris: UNESCO, 2015. 26 p. Disponível em: https://unesdoc.unesco.org/ark:/48223/ pfO000243651. Acesso em: 3 jun. 2019.

UNITED NATIONS EDUCATIONAL, SCIENTIFIC AND CULTURAL ORGANIZATION (UNESCO). Water education. Paris: UNESCO. Disponível em: $\quad$ http://www.unesco.org/new/en/natural-sciences/special-themes/ science-education/environment/water-education/. Acesso em: 3 jun. 2019.

UNITED STATES ENVIRONMENTAL PROTECTION AGENCY (USEPA). Ground Water and Drinking Water: National Primary Drinking Water Regulations. Estados Unidos: USEPA. Disponível em: https://www.epa. gov/ground-water-and-drinking-water/national-primary-drinking-waterregulations. Acesso em: 9 jun. 2019

WORLD HEALTH ORGANIZATION (WHO). Guidelines for Drinking: Water Quality. 4. ed. Genebra: WHO, 2011. Disponível em: https://www.who.int/ water_sanitation_health/publications/2011/dwq_guidelines/en/. Acesso em: 9 jun. 2019

WORLD HEALTH ORGANIZATION (WHO). International Agency for Research on Cancer (IARC). Some Organophosphate Insecticides and Herbicides. Genebra: WHO, 2015. v. 112. Disponivel em: https://www.iarc.fr/ wp-content/uploads/2018/O7/MonographVolume112-1.pdf. Acesso em: 16 jun. 2019

https://doi.org/10.1590/S1413-415220190321erratum

\section{Errata}

No artigo "Ciência ambiental: reflexões sobre o monitoramento de resíduos de agrotóxicos em águas potável, superficial e subterrânea", com número de DOI: 10.1590/S1413-415220190321, publicado no periódico Eng Sanit Ambient., v. 26, n. 2, p. 193-200, na página 193:

\author{
Onde se lia: \\ Fernando Schimdt, Alex da Mota Santos
}

Leia-se:

Fernando Schimidt, Alex Mota dos Santos 